LIAMES 5 - pp. 111-142, Primavera 2005

Fábio Bonfim Duarte

(Departamento de Lingüistica, UFMG)

\title{
Codificação de argumentos e ergatividade (cindida) em Tenetehára ${ }^{1}$
}

\begin{abstract}
This paper investigates the morphosyntactic role of the prefixes $\{\varnothing-\sim \mathbf{r}-\}$ and $\{\mathbf{i}-\sim \mathbf{h}-\}$ in argument marking. Our hypothesis is that these affixes signal the grammatical relations of adjacency and non-adjacency between complements and heads in genitive phrases, postpositional phrases and in simple and complex predicates. Our analysis shows that, in direct object focus constructions, the prefix $\{\mathbf{i}-\sim \mathbf{h}-\}$ occurs to mark the raising of either the DP subject or the object to Spec-FocP. In addition, the suffix -n (- $\varnothing$ after consonants), which occurs in oblique-topicalization signals movement of XPs to A-bar position, in the CP domain.
\end{abstract}

KEYWORDS: Tupi-Guarani; Tenetehára; Absolutive Case; Focalization and oblique topicalization.

RESUMO: Este texto examina as propriedades morfossintáticas dos prefixos $\{\varnothing-\sim$ r- $\}$ e $\{\mathbf{i}-\sim$ h- $\}$ no mecanismo de codificação dos argumentos. Nossa hipótese é que esses afixos apontam para a relação gramatical de adjacência e não-adjacência entre complementos e núcleos nos sintagmas genitivos, nos sintagmas posposicionais e nas orações independentes e dependentes. Em construções de foco de objeto (CFO), o prefixo $\{\mathbf{i}-\sim \mathbf{h}\}$ pode marcar o movimento do objeto ou do sujeito para a posição de Spec-FocP. Além disso, o sufixo $\{-\mathbf{n} \sim-\varnothing\}$ que co-ocorre com o prefixo $\{\mathbf{i}-\sim \mathbf{h}-\}$ no Indicativo II e nas CFOs sinaliza o deslocamento de sintagmas XPs para posições A-barra, no domínio do CP.

PALAVRAS CHAVE: Tupi-Guarani; Tenetehára; Caso absolutivo; Focalização e Indicativo II.

${ }^{1}$ Utilizo-me de dados de dois dialetos da língua Tenetehára, a saber: o Tembé e o Guajajára. O Tembé é falado pelos índios que vivem na fronteira entre o Pará e Maranhão, à margem paraense do rio Gurupí, e o Guajajára, pelos índios que vivem no estado do Maranhão. Parte dos dados são resultados de pesquisa de campo realizada por mim junto aos índios Tembé, entre os anos 1995 a 2001; e de textos e trabalhos publicados pela literatura lingüística [cf. Bendor-Samuel (1972); Boudin (1966, 1978); Jensen (1990) e Harrison (1986)]. E-mail do autor: bonfim@terra.com.br. 


\section{INTRODUÇÃO}

Nesse trabalho*, investigam-se as propriedades denotacionais dos prefixos $\{\mathrm{O}-\sim \mathrm{r}-\}$, $\{$ i- h- $\}$ e o seu papel na codificação dos argumentos nos constituintes de nível oracional e suboracional. Analisam-se ainda as construções que apresentam inversão de ordem básica dos constituintes, como as construções de foco de objeto (CFO), as quais apresentam a ordem OSV, e as construções com topicalizações de adjuntos (adverbiais). No âmbito dos estudos sobre a família lingüística Tupi-Guarani, considera-se que esses prefixos indicam a relação gramatical que se estabelece entre o núcleo de um sintagma (nominal, posposicional e verbal) e o seu complemento. Consoante Grannier (2005:139), esses prefixos assinalam "relações entre os núcleos e seus argumentos. Embora não indiquem nem distinção de pessoas nem as funções que desempenham, do ponto de vista da estrutura interna do constituinte, eles marcam uma função argumental". Uma maneira de captarmos essa importante intuição, no âmbito do quadro teórico da gramática gerativa, é adotarmos a hipótese de que esses prefixos são, na verdade, a manifestação na morfologia da atribuição dos Casos absolutivo, genitivo e oblíquo, dependendo se o núcleo é um verbo, um nome possuído ou uma posposição. Nessa linha de raciocínio, assumirei, no decorrer deste trabalho, que, quando os prefixos $\{\varnothing-\sim$ r- $\}$ figuram no núcleo do sintagma, é sinal de que a atribuição de Caso estrutural se dá na relação SPEC-HEAD, conforme a configuração abaixo:

(1) $\left[{ }_{\mathrm{XP}} \mathrm{DP} \quad\left[_{\mathrm{X}}{ }^{\mathrm{o}} \varnothing\right.\right.$-HEAD $\left.]\right]$

(2) $\left[_{X P} D P \quad\left[_{X}{ }^{\circ} \quad r-H E A D\right]\right]$

Já, quando são os prefixos $\{$ i- h- $\}$ que aparecem nos sintagmas verbal, genitivo e pospositivo, a atribuição de Caso não se dá na relação SPEC-HEAD, visto que o DP complemento não vem imediatamente adjacente ao núcleo, mas situado em outra posição na estrutura oracional, conforme mostramos pelas configurações abaixo.

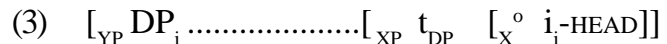

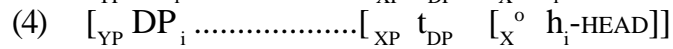

Além disso, com base na ocorrência dos alomorfes dos prefixos $\{\varnothing-\sim$ r- $\}$ e $\{\mathrm{i}-\sim \mathrm{h}-\}$, costuma-se subdividir os temas verbais, nominais e posposicionais em classe I e classe II. Os temas da classe I são os que recebem os alomorfes $\{\varnothing-\}$ e $\{i-\}$ e os da classe II, os que tomam os alomorfes $\{\mathrm{r}-\}$ e $\{\mathrm{h}-\}$, conforme vemos na tabela 1 a seguir.

\footnotetext{
* Gostaria de deixar registrado aqui meu agradecimento a dois pareceristas anônimos da Revista LIAMES, que contribuíram com críticas e sugestões para melhorar uma versão preliminar deste artigo. Parte desse texto foi apresentada durante o seminário do GEL, realizado em julho de 2004, nas dependências do IEL/Unicamp.
} 


\begin{tabular}{|l|c|l|}
\hline & $\begin{array}{c}\text { adjacência do } \\
\text { complemento }\end{array}$ & $\begin{array}{l}\text { não-adjacência do } \\
\text { complemento }\end{array}$ \\
\hline Classe I & $\varnothing-$ & i- \\
\hline Classe II & r- & h- \\
\hline \multicolumn{2}{|l|}{ TABELA 1: MARCADORES DE CASO ABSOLUTIVO, OBLÍQUO E GENITIVO } \\
\hline
\end{tabular}

Conforme veremos nas próximas seções, será a ocorrência desses prefixos no núcleo verbal que poderá engatilhar (i) o sistema (ergativo)-absolutivo em orações subordinadas temporais e em orações com alteração na ordem básica e (ii) o sistema de marcação cindida nas orações independentes. Esta cisão dependerá muitas vezes se o DP, na função sintática de sujeito ou de objeto, carrega o traço [+PESSOA] ou se o predicado monoargumental é de natureza estativa.

Este texto está organizado da seguinte maneira: na seção 2, discutimos a codificação dos argumentos nos constituintes suboracionais e oracionais em que identificamos dois sistemas: o nominativo-(acusativo) e o ergativo-(absolutivo); na seção 3, examinamos a função sintática do prefixo $\{\mathbf{i}-\sim \mathbf{h}-\}$ e do quantificador upaw na indicação de foco (contrastivo); na seção 4, investigamos a natureza morfossintática do INDICATIVO II em Tenetahára e Tupinambá, de modo a motivar uma posição funcional para abrigar XPs de natureza circunstancial; na seção 5 , analisamos se o sujeito e o objeto, que aparentemente figuram adjacente ao núcleo verbal, estão ou não na relação SPEC-HEAD; por fim, na seção 6, apresentamos a hipótese de que o critério A-barra é satisfeito nas CFOs e no INDICATIVO II sem a necessidade de o verbo mover-se para a posição de núcleo de TopP e FocP. Para tanto, propomos um mecanismo para derivar as estruturas com foco e tópico.

\section{CODIFICAÇÃODOSARGUMENTOS}

\subsection{Nos verbos transitivos das orações independentes}

Em Tenetehára, usa-se o prefixo $\{\varnothing-\sim$ r- $\}$ para os contextos em que o objeto figura na posição de especificador da categoria funcional que lhe atribui o Caso absolutivo e vem manifesto por meio de pronomes pessoais de primeira ou segunda pessoa, singular ou plural, situações nas quais pode emergir a ordem sintática OVS. Referirei, no decorrer da análise, a esta categoria como sendo $\mathrm{AbsP}^{2}$, conforme se vê nos exemplos abaixo.

\section{Tema verbal da classe I}

(5) he Ø-zuka-ràm zawar

me ABS-matar-FUT onça

"A onça me matará"

\footnotetext{
${ }^{2}$ Absolutive phrase $=$ sintagma absolutivo atribuidor do caso absolutivo.

${ }^{3}$ Remeto o leitor ao apêndice que está em anexo a este texto, para os detalhes técnicos sobre a ortografia e as abreviaturas que serão utilizadas nas transcrições dos dados.
} 
(6) ne Ø-zuka-ràm zawar

te ABS-matar-Fut onça

"A onça te matará"

(7) zane $_{\text {inclusivo }} \varnothing$-zuka-ràm zawar nos $_{\text {inclusivo }}$ ABS-matar-FUT onça

"A onça nos inclusivo $_{\text {incluá" }}$

(8) ure $_{\text {exclusivo }} \emptyset$-zuka-ràm zawar

nos exclusivi $\quad$ ABS-matar-FUT onça

"A onça nos exclusivo $_{\text {matará" }}$

(9) pe Ø-zuka-ràm zawar

vos ABS-matar-Fut onça

"A onça vos matará"

\section{Tema verbal da classe II}

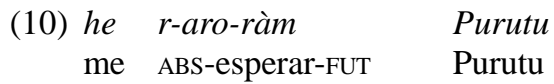

"Purutu me esperará"

(11) ne r-aro-ràm Purutu

te ABS-esperar-Fut Purutu

"Purutu te esperará"

(12) zane inclusivo r-aro-ràm Purutu

nos $_{\text {inclusivo }}$ ABS-esperar-FUT Purutu

"Purutu nos inclusivo $_{\text {esperará" }}$

(13) ure $_{\text {exclusivo }}$ r-aro-ràm Purutu

nos $_{\text {exclusivo }}$ ABS-esperar-FUT Purutu

"Purutu nos exclusivo $_{\text {experará" }}$

(14) pe r-aro-ràm Purutu

vos ABS-esperar-Fut Purutu

"Purutu vos esperará"

Já, nos contextos em que o sujeito vem representado por um pronome de segunda pessoa e o objeto, por um pronome de primeira pessoa, o verbo recebe o prefixo absolutivo $\{\varnothing-\sim \mathrm{r}-\}$, conforme se vê pelos exemplos abaixo.

\section{Tema verbal da classe I}

(15) ne he Ø-kutuk-ràm

tu me ABS-cutucar-FUT

"Tu me cutucarás" 


\section{Tema verbal da classe II}

(16) ne he r-aro-ràm

tu me ABS-esperar-FUT

"Tu me esperarás"

Contudo, quando o DP na função de sujeito é o agente (A) e vem manifesto por meio de pronomes pessoais, registra-se então a ocorrência dos prefixos nominativos ${ }^{4}$, conforme se vê pelos exemplos abaixo.

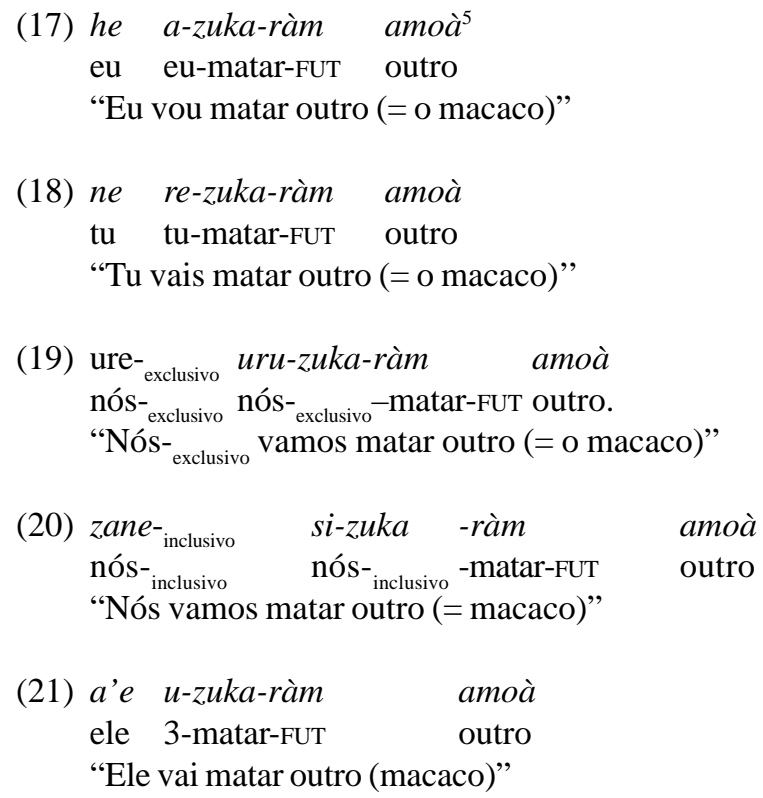

Note-se que a oposição entre os dados (5) a (16), por um lado, e (17) a (21), por outro, sinaliza a existência de um sistema cindido de codificação dos argumentos quanto ao sistema de Caso e concordância presente nos verbos transitivos, ou seja, no primeiro conjunto de dados ocorre o sistema (ergativo)-absolutivo e no segundo conjunto vigora o sistema nominativo. Percebe-se ainda que o acionamento de um ou outro sistema está intimamente correlacionado à hierarquia de pessoa (cf. Duarte, 1997, 2003), segundo a qual o prefixo de Caso que aparece no verbo transitivo, nas orações independentes, é determinado pelo DP que carrega o traço [+PESSOA], esteja ele ocupando a função de sujeito (A) ou de objeto (O). Por isso, nos exemplos (17) a (21), vemos que o verbo toma os prefixos nominativos $a-$; (e)re-; uru-; si- e $u$-, enquanto, nos exemplos (5) a (16), o verbo carrega o

${ }^{4}$ Ver no apêndice o quadro completo dos pronomes e prefixos nominativos e dos prefixos absolutivos.

${ }^{5}$ Note-se que o objeto aqui, embora esteja adjacente ao verbo, não está numa relação SPEC-HEAD, visto que não aciona o prefixo de Caso absolutivo $\{\varnothing-\sim r$ - $\}$ no verbo $-z u k a$ "matar". A razão disto deve-se ao fato de que estamos a considerar que a ocorrência do prefixo $\{\varnothing-\sim r$ - $\}$ sinaliza que o argumento move-se de sua posição de base para a posição de SPEC da categoria funcional que lhe atribui Caso absolutivo. 
prefixo absolutivo $\{\varnothing-\sim \mathrm{r}-\}$, o que sinaliza que o objeto, quando se realiza como um pronominal, vem na posição de especificador da categoria funcional AbsP que lhe atribui o Caso absolutivo, de maneira que as sentenças (15) e (16), repetidas abaixo como (22) e (23), terão a seguinte derivação sintática.

\section{Tema verbal da classe I}

(22a) ne he Ø-kutuk-ràm

tu me ABS-cutucar-FUT

"Tu me cutucarás"

(22b) $\left[_{\mathrm{TP}}\right.$ ne $\quad \mathrm{[}_{\mathrm{AbsP}}$ he $\mathrm{[}_{\mathrm{Abs}} \varnothing$-kutuk-ràm [VP ...........]]]]

\section{Tema verbal da classe II}

(23a) ne he r-aro-ràm

tu me ABS-esperar-FUT

"Tu me esperarás"

(23b) $\left[_{\mathrm{TP}} n e \quad\left[_{\mathrm{AbsP}}\right.\right.$ he $\quad\left[_{\mathrm{Abs}}\right.$ r-aro-ràm $\left.\left.\left.[\mathrm{VP} \ldots \ldots \ldots \ldots]\right]\right]\right]$

Nos contextos em que tanto o sujeito quanto o objeto são um sintagma nominal de terceira pessoa, a codificação se realiza por meio do prefixo nominativo $u$ - 'ele(s) ou ela(s)' . Além disto, em orações declarativas absolutas, cinco ordens são possíveis: VSO, SVO, VOS, SOV e OSV, conforme mostram os exemplos abaixo:

ORDEM VSO

(24) w-ekar teko wakari ita r-ehe

3-procurara gente acari* pedra oBLIQ-em

"A gente procura acari na pedra"

ORDEM SVO

(25) he-hy u-m-ur ma'er-o'o-kwer ha-we

1-mãe 3-fazer-vir coisaGEN-carne-PASS 1-DAT

"Minha mamãe deu carne para mim"

ORDEM VOS

(26) w-apy ko teko kury

3-queimar roça a gente então

"A gente queima a roça então"

ORDEM SOV

(27) Pedro $_{j} \quad i_{i}$-kyhaw u-zusi

Pedro $_{j} \quad$ GEN $_{i}$-rede 3-amarrar

"Pedro ${ }_{j}$ amarrou a rede dele,"

* Espécie de peixe de água doce; cascudo (Nota dos Editores) 
ORDEM [PP [ OSV]

(28) a'e pe ko teko u-zapo kury

3 em roça a gente 3-fazer então

"Lá, roça, a gente faz"

As duas primeiras ordens são mais produtivas, conforme mostra um estudo realizado por Duarte (1997, 2003), que teve como corpus um conjunto de 160 sentenças. Na maioria das vezes em que o sujeito e o objeto estão presentes, notou-se que a ordem predominante é $\mathrm{VSO}^{6}$, em orações principais, e $\mathrm{OV}$, em orações encaixadas que apresentam o complementizador em posição final. Notou-se ainda que, quando houver possibilidade de ambigüidade, o sujeito deve preceder o objeto, conforme mostram as orações (29) e (30), cujas ordens são SOV e VSO, respectivamente.

$\begin{array}{llll}\text { zawar kwezj } & \text { kapiwar } & \text { u-pyhyk-ràm } & \text { iko ty } \\ \text { onça aquela } & \text { capivara } & \text { 3-pegar-FuT } & \text { estar AP } \\ \text { "A onça está querendo pegar aquela capivara" }\end{array}$

(30) u-zuka Sérgio amo tazahu a'e mehe

3-matar Sérgio outro porcão esse quando

"Sérgio matou outro porcão nesse dia"

Entretanto, o objeto pode preceder (ordem VOS), ou seguir (ordem VSO) o sujeito, quando não houver possibilidade de ambigüidade para se determinar o Agente. Por isso, nas orações (31) e (32), a ordem torna-se mais livre, visto que os sintagmas nominais na função de objeto, ka'i 'macaco' e mani'ok 'mandioca', podem vir antes do sujeito, ordem VOS, ou depois, ordem VSO. Nestas orações, não há dúvida em se determinar qual dos sintagmas é o agente, o que explica a possibilidade de alternância na ordem do sujeito e do objeto.
(31a) w-apek ka'i kwahareriko wà kury (VOS)
3-despelar macaco criança estar PL então
"As crianças estavam despelando o macaco"
(31b) w-apek kwaharer ka'i iko wà̀ kury
3-despelar criança macaco estar PL então
(VSO)
"As crianças estavam despelando o macaco"
(32a) u-kamik mani'ok teko kury
3-amassar mandioca a gente então
"A gente amassa a mandioca"
(32b) u-kamik teko mani'ok kury 3-amassar a gente mandioca então
"A gente amassa a mandioca"

${ }^{6}$ Consoante Harrison (1986:408), "although Guajajara is verb-final in dependent clauses (...), the dominant order in independent clauses is VSO, in the rare cases where both S and O third person nominals are present". 


\subsection{Nos verbos intransitivos das orações independentes}

Já a codificação do argumento na função sintática de sujeito dos verbos intransitivos inacusativos que indicam deslocamento, como ir, chegar, vir, e dos intransitivos inergativos, como caminhar e correr dá-se sempre pela série de prefixos nominativos.

(33) he a-zywyr kwehe 'y apyr kutyr

eu eu-vir DPASS rio cabeceira em direção a

"Eu vim em direção à cabeceira do rio"

(34) ere re-ho kwehe 'y apyr kutyr

tu tu-ir DPASS rio cabeceira em direção a

"Tu foste em direção à cabeceira do rio"

(35) ure (u)ru-wata kwehe sibir dywyr a'e mehe

nós ${ }_{\text {exclusivo }}$ nós $_{\text {exclusivo }}$-caminhar DPASS tibir beira esse dia

"Nós caminhamos para a beira do igarapé tibir nesse dia"

(36) a'e u-hyz kwehe sibirdywyr a'e mehe

ele 3-correr DPASS tibir beira esse dia

"Ele correu para a beira do igarapé tibir nesse dia"

Nos contextos em que o sujeito não vem lexicalmente realizado por um pronome, a codificação também se dá por meio do prefixo nominativo $\{\mathrm{u}-\}$, conforme o exemplo:

(37) Purutu u-zywyr kwehe 'y apyr kutyr

Purutu 3-vir DPASS rio cabeceira em direção a

"Purutu veio em direção à cabeceira do rio"

Já com verbos inacusativos (descritivos) do tipo de serforte, estar com sono, etc., a codificação dá-se por meio dos prefixos absolutivos $\{\varnothing-\sim \mathrm{r}-\}$ e $\{\mathrm{i}-\sim \mathrm{h}-\}$, conforme mostramos abaixo:

\section{Tema verbal da classe I}

(38) he Ø-kàn

eu ABS-ser forte

"Eu sou forte"

(39) ne Ø-kàn

tu ABs-ser forte

"Tu és forte"

(40) i-kàn

ABS-ser forte

"(Ele) é forte" 


\section{Tema verbal da classe II}

(41) he r-upyhyz

eu ABS-estar com sono

"Eu estou com sono"

(42) ne r-upyhyz

tu ABS-estar com sono

"Tu estás com sono"

(43) h-upyhyz

ABS-estar com sono

"(Ele) está com sono"

Vê-se, nos dados (33) a (43) acima, a existência de um sistema de marcação de Caso cindido, o qual é condicionado pela natureza semântica do predicado. Ou seja, os verbos inacusativos estativos em (38) a (43) recebem o prefixo de Caso absolutivo, enquanto os inacusativos de movimento e os inergativos agentivos em (33) a (37) recebem prefixo de Caso nominativo. Nesse sentido, a marcação de Caso nos verbos intransitivos em Tenetehára apresenta parcialmente as características de um sistema de tipo ativo-estativo. Sendo assim, a distinção sintático-semântica, que há entre intransitivos inacusativos e intransitivos inergativos ${ }^{7}$, nem sempre é codificada inteiramente no âmbito do componente morfológico, na língua Tenetehára. Uma prova disso vem do fato de que os prefixos absolutivos não

${ }^{7}$ No âmbito da literatura gerativista, distinguem-se duas classes de verbos monoargumentais: os inacusativos e os inergativos.. Em consonância com Levin e Rappaport (1995:3): "an unergative verb takes a D-structure subject and no object, whereas an unaccusative verb takes a D-structure object, be it clausal or a simple NP - and no subject. Thus, the members of the two classes are associated with the D-Structure syntactic configurations" em (ia-b) abaixo:

(ia) Unergative verb: $\quad \mathrm{DP} \quad\left[\mathrm{VP}_{\mathrm{V}} \mathrm{V}\right]$

(ib) Unaccusative verb: $---\left[_{\mathrm{VP}} \mathrm{V}\right.$ DP/CP $]$

Por exemplo, Levin e Rappaport (1995:35-39) mostram que construções resultativas só podem ter escopo sobre DPs sujeitos de verbos inacusativos, mas nunca sobre DPs sujeitos de verbos inergativos, conforme mostra o contraste em (ii) e (iii) abaixo.

(ii) * $\operatorname{Dora}_{\mathrm{i}} \mathrm{C}_{\mathrm{VP}} \mathrm{t}_{\mathrm{i}} \mathrm{C}_{\mathrm{V}}$ shouted hoarse $]$

(iii) The river ${ }_{\mathrm{i}}\left[_{\mathrm{VP}}-\left[_{\mathrm{V}}\right.\right.$ froze $\left[_{\mathrm{SC}} \mathrm{t}_{\mathrm{i}}\right.$ solid $\left.]\right]$

Notem que o XP resultativo hoarse não pode predicar do sujeito agente Dora, em (ii), mas o XP resultativo solid pode predicar do sujeito superficial the river, em (iii), situação que evidencia que o DP the river é gerado como complemento do verbo inacusativo froze, conforme a configuração em (iv) abaixo. (iv) $\left[_{\mathrm{VP}}\right.$ froze $\left[_{\mathrm{SC}}\right.$ The river solid] $]$

Já, em (ii), o DP Dora, por ser gerado em Spec-VP, não pode formar com o XP resultativo hoarse uma $l$ clause, conforme a estrutura em (v).

(v) $*\left[_{\mathrm{VP}}\right.$ shouted $\left[_{\mathrm{SC}}\right.$ Dora hoarse $\left.]\right]$ 
ocorrem nos verbos inacusativos de processo como o verbo -mano "morrer" e o verbo estativo - $i k o^{8}$ "estar". Estes verbos, embora envolvam nitidamente um DP tema afetado, não tomam o prefixo de Caso absolutivo, como era de se supor, mas recebem, ao contrário, o prefixo de Caso nominativo $\{\mathrm{u}-\}$, conforme mostramos abaixo.

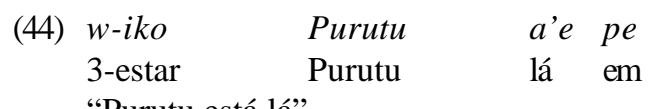

"Purutu está lá"

(45) ywyra u-mano

madeira 3-morrer

"A madeira morreu (=secou)"

Uma pesquisa futura deverá investigar se há algum outro diagnóstico, no componente gramatical, que nos permita distinguir as duas classes de verbos intransitivos: os ativos (=inergativos) e os estativos/não ativos (inacusativos).

\subsection{Nas construções genitivas}

A indicação da relação genitiva dá-se por meio da anteposição do NP POssuidor ao NP Possuído. Nestes contextos sintáticos, o prefixo $\{\varnothing-\sim$ r- $\}$ ocorre no D/NP Possuído, de modo a marcar a relação de adjacência que se estabelece entre o complemento e o núcleo do sintagma genitivo. Essa adjacência indica, portanto, que a atribuição de Caso genitivo dáse na relação Spec-HeAd. Por isso, vemos, nos exemplos abaixo, que os D/NPs -hohaw "ida" e-ekohaw "lugar" tomam os alomorfes $\{\varnothing-)$ e $\{r-\}$, respectivamente.

[D/NP POSSUIDOR-POSSUÍDO]

(46a) Tema nominal da classe I

Purutu O-ho-haw

Purutu POSS-ir-NOML

"a ida de Purutu"

(47a) Tema nominal da classe II

karaiw r-eko-haw

branco POss-lugar-NOML

"lugar do homem branco"

Não obstante, quando o POSSUIDOR não ocorre imediatamente adjacente ao POSSUíDo, ou seja, não está na relação SPEC-HEAD, porque foi omitido, o núcleo do sintagma genitivo recebe então o prefixo absolutivo $\{\mathrm{i}-\sim \mathrm{h}-\}$, comparem-se os exemplos (46a) e (47a) com (46b) e (47b) abaixo.

\footnotetext{
${ }^{8}$ Consoante Boudin (idem), o verbo iko "origina-se da pré-raiz ko, que implica uma noção de vivência".
} 


\section{Tema nominal da classe I}

(46b)

\section{i-ho-haw}

POSS-ir-NOML

"a ida dele (= de Purutu)"

\section{Tema nominal da classe II}

h-eko-haw

POss-lugar-NOML

"lugar dele (= do homem branco)"

Além dos contextos acima, o prefixo $\{\varnothing-\sim$ r- $\}$ também é usado quando a relação [POSSUIDOR-POSSUÍDO] dá-se por meio dos pronomes pessoais ocorrentes na tabela 2 abaixo.

\begin{tabular}{|c|c|}
\hline Pronomes pessoais & Significado \\
\hline he & 'eu' \\
\hline zane & 'nós inclusivo $^{\text {' }}$ \\
\hline ure & 'nós exclusivo \\
\hline ne & 'tu' \\
\hline pe & 'vós' \\
\hline \multicolumn{2}{|c|}{ TABELA 2: MARCADORES PESSOAIS } \\
\hline
\end{tabular}

Note-se que, em (48) e (49) abaixo, a ocorrência do prefixo $\{\varnothing-\sim$ r- $\}$ é exigida para marcar a relação POSSUIDOR-POSSUíDO entre os pronomes pessoais, na função de possuidores, e os substantivos -wyrapar e -àpyz, na função de possuído.

\begin{tabular}{|c|c|c|}
\hline \multicolumn{3}{|c|}{ Tema nominal da classe I } \\
\hline (48) he & $\varnothing$-wyrapar & "meu arco" \\
\hline zane & $\varnothing$-wyrapar & "nosso inclusivo $_{\text {arco" }}$ \\
\hline ure & $\varnothing$-wyrapar & "nosso exclusivo arco" \\
\hline$n e$ & $\varnothing$-wyrapar & "teu arco" \\
\hline pe & $\varnothing$-wyrapar & "vosso arco" \\
\hline \multicolumn{3}{|c|}{ Tema nominal da classe II } \\
\hline he & r-àpyz & "minha casa" \\
\hline zane & r-àpyz. & "nossa ${ }_{\text {inclusivo }}$ casa" \\
\hline ure & r-àpyz & "nossa ${ }_{\text {exclusivo }}$ casa" \\
\hline ne & r-àpyz & "tua casa" \\
\hline pe & r-àpyz. & "vossa casa" \\
\hline
\end{tabular}

Semelhantemente aos exemplos (46b) e (47b), quando o POSSUIDOR não está presente, seja porque foi omitido ou porque foi deslocado para outra posição na sentença, usa-se então o prefixo $\{$ i- h- $\}$, o qual tem a função de denotar a não adjacência do complemento, conforme se vê nos exemplos abaixo. 
(50) i-wyrapar "arco dele(a)"

(51) h- àpyz "casa dele(a)"

\subsection{Nos sintagmas posposicionais}

Os sintagmas posposicionais em Tenetehára, doravante PPs, apresentam sistematicamente a ordem $\left[{ }_{\mathrm{XP}} \operatorname{COMPL}\left[{ }_{\mathrm{X}} \mathrm{P}^{\circ}\right]\right]$ e, em geral, a posposição (= núcleo do sintagma pospositivo), assim como os verbos e os nomes, também flexionam, pois podem receber o prefixo $\{\varnothing-\sim \mathrm{r}-\}$, para indicar a adjacência do D/NP complemento, conforme abaixo.

COMPLEMENTO ADJACENTE AO NÚCLEO $\mathrm{P}^{\circ}$

Tema posposicional da classe I

(52a) ko Ø-pupe

roça OBLIQ-dentro de

"Dentro da roça"

\section{Tema posposicional da classe II}

(53a) ko r-ehe

roça OBLIQ-em

"Na roça"

Nos contextos em que o DP complemento ko "roça" não vem imediatamente adjacente, o núcleo $\mathrm{P}^{\circ}$ recebe o prefixo $\{\mathrm{i}-\sim \mathrm{h}-\}$, para denotar que o complemento não vem expresso lexicalmente no sintagma pospositivo, conforme se vê abaixo.

COMPLEMENTO DA POSPOSIÇÃO NÃO ADJACENTE

Tema posposicional da classe I

(52b) $i$-pupe

OBLIQ-PSP

"Dentro dela (a roça)"

Tema posposicional da classe II

(53b) h-ehe

OBLIQ-PSP

"Nela (a roça)"

Além das posposições - ehe e - pupe, há ainda outras que codificam diferentes nuances de significado, como direção, companhia, movimento, etc., conforme abaixo:

\section{(54) Temas da classe I}

$\begin{array}{ll}\text {-aikweramo } & \text { "atrás de" } \\ \text {-upi } & \text { "dentro de, com" } \\ \text {-kutyr } & \text { "em direção a" }\end{array}$




\section{(55) Temas da classe II \\ - pe -me "em" \\ -iruramo: "junto de; na companhia de" \\ -wi "originário de"}

\subsection{Nas orações temporais}

De acordo com a análise de Duarte (1997, 2003), as orações temporais que apresentam o complementizador final mehe apresentam ordem fixa dos constituintes, uma vez que o objeto direto sempre precede o verbo, prevalecendo a ordem OV. Adicionalmente, nota-se que verbos auxiliares ocorrem em regra após o complementizador, constituindo a ordem [OV [mehe [ Aux ]], conforme o exemplo abaixo

(56a) Purutu $\quad$ w-exak

Purutu 3-ver

(56b)[zawar ${ }_{\mathrm{i}}$ tapi'ir $\boldsymbol{u}_{\mathrm{i}}$-zuka mehe iko]

onça $_{i}$ anta ela-matar comp estar

"Purutu viu que a onça estava matando a anta"

Quanto ao sistema de codificação dos argumentos, pode-se afirmar que a gramática dos falantes mais velhos ainda aciona o sistema de codificação (ergativo)-absolutivo. Neste sistema, o verbo recebe o prefixo de Caso absolutivo $\{\varnothing-\sim r-\}$ quando o DP objeto de verbos transitivos e o DP sujeito de verbos monoargumentais vêm na posição de SPEC na categoria funcional que lhes atribui Caso. A hierarquia de pessoa é irrelevante nessas orações. Esse sistema de codificação é ilustrado pelos dados abaixo.

\section{Verbos transitivos}

(57a) Purutu $\quad$ w-exak

Purutu 3-ver

(57b) [karaiw he Ø-pyhyk mehe]

não-índio eu ABS-pegar COMP

"Purutu viu [que/quando o homem branco (não-índio) me apanhou]"

(58a) Purutu $\quad$ w-exak

Purutu 3-ver

(58b)[karaiw tapi'ir Ø-pyhyk mehe]

não-índio anta ABS-pegar COMP

"Purutu viu [que/quando o homem branco (não-índio) apanhou a anta]"

(59a) Purutu $\quad$ w-exak

Purutu 3-ver 


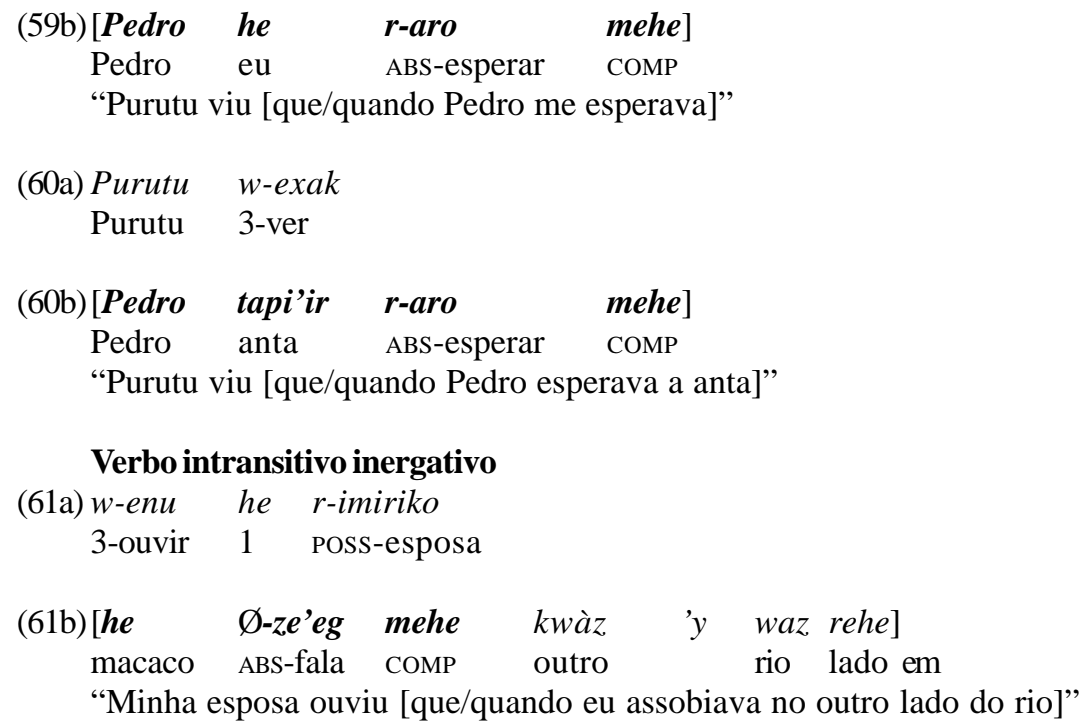


$\begin{array}{rll}\text { (65b) }\left[\boldsymbol{w}_{\boldsymbol{i}} \text {-erimiriko }\right. & \text { r-urywete } & \text { mehe }] \\ \mathrm{CORR}_{i} \text {-esposa } & \text { ABS-estar bem/feliz } & \text { COMP }\end{array}$

"Purutu foi para Belém, [quando sua ${ }_{i}$ esposa estava bem]"

Observem que, nos exemplos em (b), a codificação do objeto e do sujeito dos verbos monoargumentais dá-se por meio do prefixo absolutivo $\{\varnothing-\sim$ r- $\}$. Contudo, se o complemento ou o sujeito vierem omitidos por razões discursivas, o verbo toma o prefixo absolutivo $\{\mathrm{i}-\sim \mathrm{h}-\}$, conforme exemplos abaixo.

\section{Verbos transitivos}

(66a) Purutu $\quad$ w-exak

Purutu 3-ver

(66b) [karaiw i-pyhyk

mehe]

não-índio

ABS-pegar COMP

"Purutu viu [que/quando o homem branco (não-índio) a apanhou (a anta)]"

(67a) Purutu $\quad$ w-exak

Purutu 3-ver

$\begin{array}{ccc}\text { (67b) }[\text { Pedro } & \text { h-aro } & \text { mehe }] \\ \text { Pedro } & \text { ABS-esperar } & \text { COMP } \\ \text { "Purutu viu [que/quando Pedro a esperava (a anta)]" }\end{array}$

Verbo intransitivo inergativo

(68a) w-enu he r-imiriko

3-ouvir 1 POss-esposa

(68b) [_ $\begin{array}{ccccc}\boldsymbol{i} \text {-ze'eg } & \text { mehe } & k w a ̀ z & \text { 'y } & \text { waz rehe }] \\ \text { ABS-fala } & \text { COMP } & \text { outro } & \text { rio } & \text { lado em }\end{array}$

"Minha esposa ouviu [que/quando (ele) assobiava no outro lado do rio]"

A pesquisa de campo nos mostrou haver, entretanto, uma alteração no sistema de codificação apresentado acima, especialmente entre os falantes das gerações mais novas dos Tenetehára Tembé, residentes nas aldeias localizadas à margem direita do Rio Gurupi, de tal sorte que os verbos transitivos e os intransitivos admitem o sistema nominativo. A inovação que se observa é a presença dos prefixos nominativos para codificar o sujeito, como se pode notar no exemplo (56b), repetido abaixo como (69b).

(69a) Purutu $\quad$ w-exak

Purutu 3-ver

${ }^{9}$ Um dos pareceristas sugere que se averigúe o que ocorre quando o sujeito e o objeto são nulos. Por razão de falta de tempo e de espaço, deixo para pesquisa futura a análise desses contextos entre os falantes da geração mais nova dos Tenetehára Tembé. 
(69b) $\left[\right.$ zawar $_{\mathrm{i}}$ tapi'ir $^{9} \quad u_{\mathrm{i}}-z u k a$ mehe iko $]$ onça $_{\mathrm{i}}$ anta ela-matar comp estar

"Purutu viu que/quando a onça estava matando a anta"

Veja que, em (69b), o verbo transitivo não codifica o DP objeto tapi' ir "anta", e sim o DP sujeito zawar "onça", o que nitidamente contrasta com o sistema (ergativo)-absolutivo, que vimos nos exemplos (57b) a (65b). Além de contextos com verbos transitivos, as orações temporais abaixo retiradas de textos narrativos e de elicitações feitas com os informantes mostram a ocorrência dos prefixos nominativos também em verbos intransitivos. Em (70) e (71), por exemplo, os sintagmas nominais pira 'peixe' e kudàtà' $i$ 'moça', ambos na função sintática de sujeito, são referidos nos verbos das orações temporais pelo prefixo nominativo $\{u$ - $\}$.

(70) u-pyhyk pira $u_{i}-k a^{\prime} u \quad$ mehe kury

3-pegar $\quad$ peixe $_{i} \quad 3_{i}$-ficar bêbado comP agora

"(A gente) pega o peixe ${ }_{i}$ quando (ele ${ }_{i}$ ) fica bêbado"

(71) a-mume'u-ràm ma'e nazewe

1-contar-INTC coisa assim

kuzàtà'i u-zemuny'ar mehe

moça 3-ter a primeira menstruação COMP

"Eu vou contar sobre quando a moça tem a primeira menstruação"

Conclui-se, portanto, que, nas orações temporais com mehe, o sistema ergativo alterna com o sistema nominativo, possivelmente em razão de mudanças estruturais por que está passando a língua Tenetehára.

\section{CONSTRUÇÕES COM FOCO DE OBJETO}

Nos contextos não-marcados ${ }^{10}$, em que tanto o sujeito quanto o objeto são realizados por D/NPs não pronominais, a codificação do sujeito dá-se por meio do prefixo nominativo $\{u$ - $\}$, conforme exemplo (72) abaixo:

${ }^{10}$ Estamos a considerar marcados aqueles contextos em que, por exemplo, o objeto é elevado para a periferia esquerda da oração, alterando assim a ordem básica, como acontece no exemplo (ii) abaixo:

(i) u'u teko upaw pira

3-comer a gente todo o peixe

"A gente comeu todo o peixe"

(ii) upaw pira teko i-'u-n

todo o peixe a gente NC-comer-DESLC

"Todo o peixe, a gente comeu"

Veja que, nesse exemplo, a presença do prefixo $\{i-\}$ e do sufixo $\{-n\}$ apontam para o fato de que o objeto upaw pira é deslocado para uma posição A-barra, no domínio do sistema CP. 
(72) u'u teko upaw pira

3-comer a gente todo opeixe

"A gente comeu todo o peixe"

Na língua Tenetehára, é bastante comum a ocorrência do prefixo $\{\mathrm{i}-\sim \mathrm{h}-\}$ em contextos nos quais o objeto, por carregar o traço [+FOC], é deslocado para uma posição no domínio do CP. Nesses contextos, verifica-se que a ordem VSO é alterada, casos em que emerge a ordem OSV, conforme notamos pelo contraste entre os exemplos (a) e (b) abaixo.

$\begin{array}{llllll}\text { (73a) } \boldsymbol{u} \text {-mua'ag } & \text { teko } & \text { ywyra inimo } & \text { pihun } & \text { pupe } & \text { kury } \\ \text { 3-marcar } & \text { a gente } & \text { madeira fio } & \text { preto } & \text { com } & \text { então } \\ \text { "A gente marca a madeira com fio preto então" } & & & \end{array}$

$\begin{array}{cccc}\text { (73b) upaw } & \text { ywyra teko } & \text { i-mua'ag-O } & \text { kury } \\ \text { toda } & \text { madeira a gente } & \text { ABS-marcar-DESLOC } & \text { então } \\ \text { "ToDA A MADEIRA, a gente marca então" } & \end{array}$

(74a) w-exak Fábio Márcia

3-ver Fábio Márcia

"Fabio viu a Márcia"

\section{(74b) upaw $^{11} \quad$ Márcia $\quad$ Fábio $\quad \boldsymbol{h}$-exak $\quad \varnothing$ toda Márcia Fábio ABS-ver- DESLOC \\ "Toda a Márcia, Fabio viu" \\ [lit: viu-a por inteiro, integralmente, e não parcialmente]}
(75a) $u$-'u teko pira
3-comer a gente peixe
"A gente come peixe"

(75b) upaw pira teko i-'u-n

todo peixe a gente ABS-comer-DESL

"TODO O PEIXE, a gente come"

${ }^{11}$ Boudin (1978:282) arrola os seguintes significados para o quantificador upaw, conforme abaixo:
(i) upa(w) katete "todos sem exceção"
(ii) $\quad u p a(w)$ katu "completamente tudo"

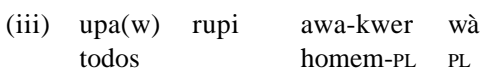
"todos os homens"
(iv) $\operatorname{upa}(\mathrm{w})$ rupi katete $\mathrm{n}-\mathrm{ur}-\mathrm{i}$ wà pe wi todos integralmente PL C-vir-DESL PL lá de


Observe que a principal diferença entre as sentenças (a) e (b) é que, nestas últimas, o DP objeto, por estar focalizado, desloca-se para uma posição na periferia esquerda da oração, possivelmente para atender a exigências do critério A-barra. Além disso, o verbo tem sua morfologia flexional alterada, ocorrendo nesses casos o prefixo $\{\mathbf{i}-\sim \mathbf{h}-\}$ e o sufixo $\{-\mathbf{n}(\mathbf{i})\}$. Notem ainda que, nas sentenças (73b), (74b) e (75b), o DP objeto figura precedido pelo quantificador upaw "todo(s), toda(s)", o qual indica que a ação de marcar a madeira foi realizada integralmente, e não parcialmente. A ocorrência do quantificador upaw em construções de foco de objeto, doravante CFOs, sugere que a ação/evento é focalizada em sua totalidade, e não parcialmente, por isso sua presença desempenha papel crucial para determinação da interpretação de foco contrastivo. Uma evidência adicional a favor dessa análise surge do fato de que o prefixo $\{\mathbf{i}$ - $\}$ também ocorre em CFOs de outra língua do tronco Tupi, a língua Meken. Galúcio (2002:274) mostra que, quando o objeto é focalizado, o verbo toma o prefixo $\{\mathbf{i}-\}$, conforme se vê pelos exemplos abaixo.

(76a) assi nwa ẽ $\quad \tilde{o}-a \quad$ o-arop-na

mãe panela dar-vT 1-coisa-vbrlz

"Minha mãe deu a panela para mim (para ser a minha coisa)"

(76b) ywa $\quad$ te $\quad$ asi $\quad$ i-õp o-arop-na

panela FOC mãe OBJ-dar 1-coisa-vbrlz

"Foi Panela que minha mãe me deu (para ser a minha coisa)"

Veja-se que, no exemplo (76a), os constituintes principais da sentença ocorrem na ordem não marcada SOV, por essa razão o verbo não exibe o prefixo absolutivo \{i-\}. Por sua vez, em (76b), como ocorre focalização do objeto, o verbo tem de receber este prefixo e a ordem SOV é alterada para OSV, situação muito similar da que acontece nos exemplos (73b), (74b) e (75b) do Tenetehára. Na língua Tupinambá, o prefixo \{i-\} também aparece no verbo transitivo, quando o DP objeto não está imediatamente adjacente ao verbo transitivo, mas deslocado para uma posição A-barra, conforme se vê pelos dados abaixo, retirados de Rodrigues (1953:133).

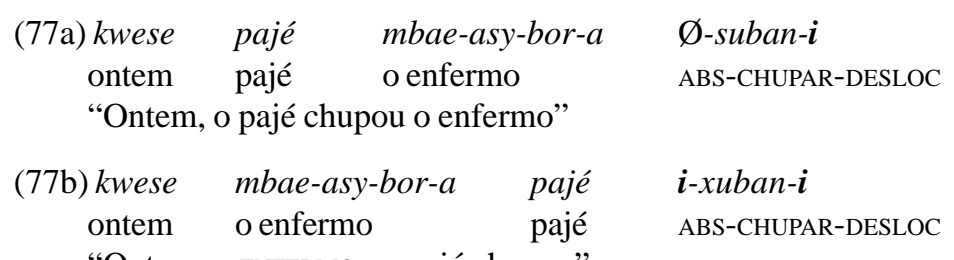

"Ontem, o ENFERMO, o pajé chupou"

Em (77b), como o DP mbae-asy-bor-a “o enfermo" não vem adjacente ao verbo, mas deslocado para antes do sujeito, o verbo toma o prefixo $\{\mathrm{i}-\}$ e a ordem [ADV [SOV]] é alterada para [ADv [OSV]]. Diferentemente, em (77a), o verbo recebe o prefixo absolutivo $\{\varnothing-\}$, uma vez que o DP objeto está na posição de especificador de AbsP. Com base nessas 
observações, uma maneira de captarmos o padrão flexional que os verbos tomam nas CFOs é admitirmos que o prefixo $\{\mathbf{i}-\sim \mathbf{h}-\}$ tem a função de assinalar o movimento do objeto para posição estrutural de foco, mais especificamente para SPEC-FocP, e que o aparecimento do sufixo $\{-\mathbf{n} \sim-\varnothing\}$ reflete (i) o deslocamento de constituintes para a periferia esquerda da oração e (ii) a mudança na ordem canônica dos constituintes das orações, as quais passam de VSO, em Tenetehára, e SOV, em Tupinambá e Meken, para OSV nas três línguas.

Averiguamos na próxima seção as construções do modo indicativo II que exibem padrão flexional muito semelhante ao das CFOs acima, visto que também possuem XPs deslocados para a periferia esquerda e acionam os prefixos $\{\varnothing-\sim \mathbf{r}-\} \mathbf{e}\{\mathbf{i}-\sim \mathbf{h}-\}$, perfazendo, assim, um sistema de marcação de Caso (ergativo)-absolutivo, semelhante ao visto na orações temporais em 2.4 .

\section{INDICATIVO II}

Orações independentes que possuem um sintagma XP de natureza circunstancial ou locativa, que em geral vem deslocado para o início da oração, precedendo todos os outros constituintes da sentença, engatilham mudança no padrão flexional do verbo. Consoante Rodrigues (2001:88), o verbo dessas orações é marcado "por um sufixo modal específico, o qual tem sido tratado como marca de um modo indicativo II (...) ou modo circunstancial (...)". Nessas construções, o verbo toma o prefixo $\{\varnothing-\sim$ r $\}$ ou $\{$ i- $\sim$ s- $\}$, dependendo se o objeto direto ou o sujeito de verbos inacusativos estão adjacentes ou não ao verbo, conforme exemplos abaixo:

\section{MODO INDICATIVO II}

(78) oje'i apyaß-a

$\begin{array}{llll}\text { hoje }^{j} & \text { homem-ARG } & \begin{array}{l}\text { tapi'ir- } a_{\mathrm{i}} \\ \text { anta-ARG }\end{array} & \boldsymbol{r}_{\mathrm{i}} \text {-epják- } \boldsymbol{i}_{j} \\ \text { ABS-ver-IND II }\end{array}$

"Hoje um homem viu uma anta"

(79) kwesé $_{j} \quad$ Pedro $_{\mathrm{i}} \quad \emptyset_{\mathrm{i}}$-só-w ontem Pedro ABS-ir-IND II

"Ontem Pedro foi"

(80a) kwesé $\quad k a^{\prime} a-\varnothing \quad r$-upi $\quad o_{\mathrm{i}}$-wata- $\beta$ o $\quad$ Pedro ${ }_{\mathrm{i}} \quad \boldsymbol{r}_{\mathrm{i}}$-opár- $\boldsymbol{i}_{j}$ ontem mato-ARG OBLIQ-por ele-andar-GER Pedro ABS-perder-se-IND II "Ontem, andando pelo mato, Pedro se perdeu"

(80b)kwesé $\quad k a a^{\prime} a-\varnothing \quad r$-upi $\quad$ Pedro $_{\mathrm{i}} \quad o_{\mathrm{i}}$-wata- $\beta o \quad \boldsymbol{s}_{\mathrm{i}}$-opár-i ontem mato-ARG OBLIQ-por Pedro ele $_{\mathrm{i}}$-andar-GER ABS-perder-se-IND II "Ontem, Pedro andando pelo mato, (ele) se perdeu" 
MODO INDICATIVO I

$\begin{array}{ccc}\text { (81a) } \begin{array}{c}\text { apyáß- } a_{j} \\ \text { homem-ARG } i\end{array} & \text { tapi'ir- } a_{\mathrm{i}} & o_{j} \text { - } s_{\mathrm{i}} \text {-epják } \\ \text { hoje } & \text { anta-ARG } & \text { ele-ABS-ver }\end{array}$

"Um homem viu hoje uma anta"

MODO INDICATIVO II

(81b) oje’ $i_{j} \quad$ apyáß-a tapi'ir-a $a_{i} \boldsymbol{r}_{i}$-epják-i

hoje homem-ARG anta-ARG ABS $_{i}$-ver-IND II

"Um homem viu hoje uma anta"

Em Tupinambá, o sufixo $\{-\mathbf{i} \sim \mathbf{- w}\}$ aponta para o fato de que um XP circunstancial foi deslocado para o início da oração. Em (78) e (81b), esse XP é o advérbio oje' $i$ "hoje”, e, em (79), é o advérbio temporal kwesé, e, em (80a) e (80b), esse XP corresponde à oração circunstancial que foi anteposta ao predicado principal. Já o prefixo de Caso absolutivo $\{\varnothing$ $\sim \mathbf{r}-\}$ assinala que o complemento está na posição de SPEC de AbsP. O prefixo \{s- $\}$, em (80b), denota que o sujeito moveu-se para outra posição em relação àquela em que se encontra o verbo -opári "perder-se".

Por sua vez, a língua Tenetehára também apresenta padrão flexional muito semelhante ao do Tupinambá no INDICATIVo II, já que os prefixos absolutivas são também acionados e há ocorrência do sufixo $\{-\mathbf{n}(\mathbf{i})\}$, para indicar deslocamento de constituintes para a periferia esquerda, resultando em mudança da ordem básica dos constituintes. Harrison (1986:417) trata o INDICATIVO II como sendo resultado de topicalização de elementos oblíquos e de natureza circunstancial/locativa para o início da oração. Segundo o autor:

"If an adverb or a postpositional phrase is moved (for discourse-related reasons) to the front of a clause, or at least to a position before the verb, and if the subject is third person, the verb marking is (ergative-)absolutive as in dependent clauses, and the oblique-topicalization is registered in the verb by the suffix - $n$ (-Ø after consonants) (...) It is not a true promotion, in the sense where passive promotes a direct object to subject. Although there are changes in the verb, a transitive verb remains transitive, and the oblique element that would seem to be promoted does not lose its oblique marking (postposing)"

Os dados abaixo mostram a realização do INDICATIVo II em Tenetehára. Note-se, em particular, o contraste entre os exemplos (82a) e (82b), por um lado, e (83a) e (83b), por outro. Nos exemplos (a), observa-se que os constituintes estão na ordem canônica e o sistema de codificação dos argumentos é o nominativo. Já, nos exemplos (b), o sistema de codificação é o (ergativo)-absolutivo e a ordem dos constituintes é alterada, ordem [Adv [pro V]] em função do deslocamento do XP a'e pe "lá" para o início da oração.

$\begin{array}{ccc}\text { (82a) w-iko a'e } & p e \\ \text { 3-estar lá } & \text { em } \\ \text { "(Ele) está lá" } & \end{array}$




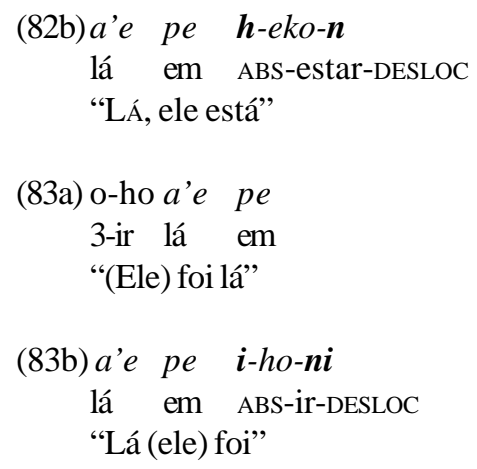

Nos exemplos acima, nota-se que o prefixo $\{\mathbf{i}-\sim \mathbf{h}-\}$ faz referência aos sujeitos dos verbos inacusativos que foram omitidos. Comparando os dois conjuntos de dados, observa-se que o sufixo $\{-\mathbf{n}(\mathbf{i}) \sim-\varnothing\}$ do Tenetehára e o sufixo $\{-\mathbf{i} \sim-\mathbf{w}\}$ do Tupinambá refletem o fato de ter havido o deslocamento de constituintes XPs circunstanciais para o domínio CP. Por esta razão, as propriedades denotacionais desses afixos nas duas línguas permitem-nos motivar duas categorias funcionais no domínio CP: uma de natureza tópica/circunstancial, a que chamaremos de TopP, local para onde os XPs de natureza locativa e temporal se movem; e outra de natureza focal para onde constituintes focalizados se deslocam, conforme a configuração em (84).

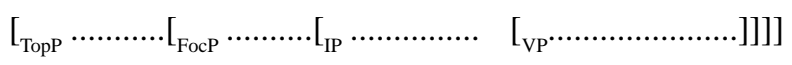

Minha hipótese é que a morfologia verbal reverbera as duas categorias funcionais propostas em (84), de sorte que a co-ocorrência do prefixo $\{\mathbf{i}-\sim \mathbf{h}-\}$ com os sufixos $\{-(\mathbf{n}) \mathbf{i} \sim-\varnothing\}$ codifica o fato de XPs circunstanciais e DPs objetos se moverem para posições de especificadores em categorias funcionais relacionadas a tópico e foco, na periferia esquerda da oração. Por isto, com base na estrutura oracional proposta em (84), assumirei, por exemplo, que a sentença (85a) possui a estrutura em (85b) e que a sentença (86a), a estrutura em (86b). Note-se que há uma nítida correlação entre a ocorrência do PP locativo $a^{\prime} e$ pe em Spec-TopP e o aparecimento do sufixo $\{-\mathbf{n}(\mathbf{i})\}$ no verbo, por um lado, e, entre o deslocamento do objeto upaw pira "todo o peixe" para Spec-FocP e o prefixo absolutivo de não-adjacência $\{i-\}$ no verbo transitivo -'u “comer", por outro lado. Em suma, o que notamos é que a morfologia verbal é sensível a movimento de XPs (adjuntos e complementos) para a posição de especificador de TopP e FocP.

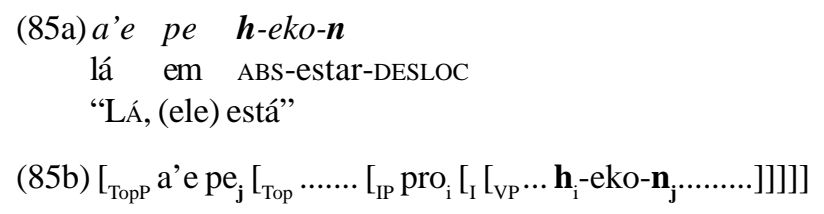


$\begin{array}{clll}\text { (86a) upaw } & \text { pira } & \text { teko } & \boldsymbol{i} \text {-'u-n } \\ \text { todo } & \text { peixe } & \text { a gente } & \text { ABS-comer-DESL }\end{array}$

"TODO O PEIXE, a gente come"

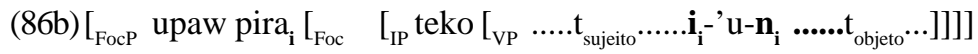

A proposta de derivação em (85b) e (86b) nos permite intuir que o verbo não é movido para núcleo de TopP nem para núcleo de FocP, mas permanece numa posição mais baixa na estrutura. Outro ponto importante a observar é que o prefixo absolutivo $\{\mathrm{h}-\sim \mathrm{i}-\}$ faz referência ao objeto nas construções transitivas e ao sujeito nos predicados monoargumentais. A questão do estatuto sintático de $\operatorname{Top}^{\circ} \mathrm{e} \mathrm{Foc}^{\circ} \mathrm{e}$ a explicação da razão pela qual o verbo não se move até os núcleos Top e e Foc ${ }^{\circ}$ será objeto de análise na seção 6.

Na próxima seção, investigamos os contextos sintáticos em que, embora ocorra o prefixo $\{$ i- $\sim$ h- $\}$, mesmo assim é possível o objeto e o sujeito virem aparentemente adjacentes a verbos transitivos e monoargumentais.

\section{CONTEXTOS DEAPARENTEADJACÊNCIADOSUJEITOE DO COMPLEMENTO}

Conforme vimos assumindo até aqui, a principal função do prefixo $\{\mathrm{i}-\sim \mathrm{h}-\}$ é (i) atribuir Caso absolutivo nos predicados verbais; (ii) fazer referência ao DP sujeito/objeto que não está na posição de SPEC da categoria funcional que lhe atribui caso. Contudo, o Tenetehára difere neste aspecto do Tupinambá e de outras línguas da família Tupi-Guarani, por exibir ambientes em que, embora o objeto e o sujeito estejam aparentemente adjacentes ao núcleo na ordem linear, o verbo não toma o prefixo $\{\varnothing-\sim \mathrm{r}-\}$, mas sim o prefixo $\{\mathrm{h}-\sim \mathrm{i}-\}$, o qual indica a não-adjacência do complemento. Tal situação ocorre, por exemplo, (i) nas construções com predicado descritivo, exemplos (87) e (88); (ii) nas orações subordinadas com verbos transitivos e inacusativos, exemplos (89b), (90) e (91); (iii) em construções que exibem o padrão flexional do indicativo II (modo circunstancial), exemplos (92b) a (94), e (iv) em nominalizações de predicados transitivos, exemplos (95) e (96).

(87) Pedro i-kàn

(i) PREDICADOS DESCRITIVOS

Pedro ABS-ser forte

"Pedro é forte"

(88) Pedro h-upyhyz

Pedro abs-estar com sono

"Pedro está com sono"

(ii) ORAÇõES SUbORDINADAS

(89a) e-ho ko pe ty

2-IMP-ir roça para AP

"Venha para a roça" 
(89b)awaxi i-’u-n pà

milho ABS-comer-DESLC COMP

"na finalidade de comer o milho"

COM VERBOS INACUSATIVOS

(90) Sérgio w-exak Pedro i-ho mehe.

Sérgio 3-ver Pedro ABS-ir COMP

Sérgio viu quando Pedro (ele) ia"

(91) w-exak Sibazawar pinim $\boldsymbol{h}$-eko-n $\boldsymbol{n}^{\mathbf{1 2}}$ mehe

3-ver Siba onça pintada ABS-estar-DESLOC COMP

"Siba viu quando a onça (ela) estava lá"

(iii) INDICATIVO II

(92a) u-pyta

3-ficar

(92b)a'e rupi tywyr i-ho-ni.

porém o irmão ABS-ir-DESLOC

"Ele ficou, porém o irmão foi embora"

(93) ma'e pe ru'u Pedro i-ho-ni kury?

onde para $\mathrm{Q}$ Pedro ABS-ir-DESLOC agora

"Para onde que Pedro foi?"

(94) ma'e pe te Pedro i-ho-n(i)

onde COMP Pedro ABS-ir-DESLOC

"Onde que Pedro foi"

(iv) NOMINALIZAÇÕES

(95) tyràm $_{\mathrm{i}} \boldsymbol{i}_{\mathrm{i}}$-apo-haw teko wi

farinha $_{i}$ ABS $_{\mathrm{i}}$-fazer-NOML a gente por

"A feitura da farinha pela gente"

(96) $z$ z'i $\boldsymbol{i}_{\mathrm{i}} \quad \boldsymbol{i}_{\mathrm{i}}$-mu-me'u-haw a'e kury

rã $\quad$ ABS $_{\mathrm{i}}$-CAUS-contar-NOML ele ${ }_{\mathrm{i}}$ então

"A estória dela, a rã"

${ }^{12}$ Um dos pareceristas chamou minha atenção para o fato de o sufixo $\boldsymbol{- n}(\boldsymbol{i})$ aparecer no verbo da oração subordinada, o que é inusitado, visto que era de se esperar a ocorrência desse afixo apenas em orações com CFOs e com deslocamento de XPs circunstanciais. Sua ocorrência em (72) pode estar relacionada ao deslocamento do sujeito da oração para uma posição acima do IP. Contudo, por motivo de espaço e de tempo, não poderei discutir em detalhe o escopo desse afixo nas orações temporais com o complementizador mehe. 
O fato curioso nos dados acima é que o verbo sempre toma o prefixo $\{\mathbf{i}-\sim \mathbf{h}-\}$, muito embora o sujeito dos verbos monoargumentais e o DP objeto estejam adjacentes aos núcleos que lhes atribuem Caso. Sendo assim, nossa análise precisa determinar como é possível a ocorrência do prefixo de Caso absolutivo $\{\mathbf{i}-\sim \mathbf{h}-\}$, tendo em vista que ele em geral denota a não-adjacência do objeto e do sujeito. Uma maneira é, então, estipularmos que a adjacência é apenas aparente e que os DPs sujeito e o objeto, de fato, estão numa posição derivada, fora do predicado, provavelmente em decorrência de movimentos sintáticos para satisfazer a expedientes como focalização e topicalização. Com base nessa hipótese, proporemos a existência de categorias funcionais que alojam os DPs sujeito e objeto e que, portanto, os separam do verbo nas construções (87) a (96). Dessa maneira, o sujeito da sentença (87), repetida abaixo como (97), deve figurar numa categoria funcional diferente daquela em que está o verbo ikàn. Isto nos permitirá propor que possivelmente o sujeito entra na derivação carregando um traço ininterpretável de foco [ $u$ FOCO], o qual é verificado no ponto da derivação em que se move para SPEC-FocP. Nessa linha de investigação, podemos considerar que a ocorrência do prefixo absolutivo $\{\mathbf{i}-\}$ no verbo $-k a ̀ n$, em vez do prefixo $\{\varnothing-\}$, tem a função de sinalizar que o DP sujeito está fora do IP, possivelmente na posição de especificador de FocP, conforme a configuração em (97b) abaixo.

$$
\begin{aligned}
& \text { (97a) Pedro } \quad \text { i-kàn } \\
& \text { Pedro ABS-ser forte } \\
& \text { "Pedro é forte" } \\
& \text { (97b) }\left[_ { \mathrm { FocP } } \text { Pedro } _ { \mathrm { i } } \left[_{\mathrm{Foc}} \ldots . .\left[_{\mathrm{IP}} \ldots . \mathrm{t}_{\mathrm{i} . . . .}\left[\mathrm{i}_{\mathrm{i}} \mathbf{i}_{\mathrm{i}} \text {-kàn }\left[{ }_{\mathrm{VP}} \ldots \ldots . .\right]\right]\right]\right.\right.
\end{aligned}
$$

A proposta de derivação em (97b) nos permitirá explicar uma importante diferença entre o Tenetehára e o Tupinambá no que se refere ao padrão flexional do verbo no INDICATIVO II e à estrutura da oração. Em Tupinambá, vimos que, quando o sujeito vem na posição de SPEC da categoria que lhe atribui Caso estrutural, o verbo em geral toma o prefixo $\{\varnothing-\sim \mathbf{r}-\}$, o que vem sinalizar que a posição do DP sujeito é interna ao predicado e não externa a ele, mais especificamente em SPEC-IP, conforme a proposta derivacional em (98b).

$$
\begin{aligned}
& \text { (98a) kwesé Pedro Ø-só-w } \\
& \text { ontem Pedro ABS-ir-IND II } \\
& \text { "Ontem Pedro foi" } \\
& \text { (98b) } \left.\left[_{\mathrm{CP}} \text { kwesé }\left[_{\mathrm{IP}} \text { Pedro [ }{ }_{\mathrm{I}} \text {-só-w }\left[_{\mathrm{VP}} \ldots \ldots \ldots \ldots . . . . . . .\right]\right]\right]\right]
\end{aligned}
$$

Todavia, no INDICATIVO II em Tenetehára, a situação é distinta, já que, embora esteja o sujeito aparentemente adjacente ao verbo na ordem linear, o verbo mesmo assim apresenta o prefixo absolutivo $\{\mathrm{i}-\}$, conforme se vê nos exemplos repetidos abaixo.

\section{(99a) u-pyta}

3-ficar 
(99b)a'e rupi tywyr i-ho-ni

porém o irmão ABS-ir-DESLOC

"Ele ficou, porém o irmão foi embora"

$\begin{array}{clll}\text { (100) ma'e pe ru'u Pedro } & \text { i-ho-ni } & \text { kury? } \\ \text { onde para Q Pedro } & \text { ABs-ir-DESLOC } & \text { agora } \\ \text { "Para onde que Pedro foi?" } & & \end{array}$

$\begin{array}{lll}\text { (101) ma'e pe te Pedro i-ho-n }(\boldsymbol{i}) \\ \text { onde } & \text { cOMP Pedro } & \text { ABS-ir-DESLOC } \\ \text { "Onde que Pedro foi" } & \end{array}$

A ocorrência do prefixo $\{\mathrm{i}-\}$ nos dados acima pode ser explicada se aplicamos a mesma hipótese de derivação sintática sugerida em (97b), e postulamos que o DP sujeito não está dentro do predicado, i.e., na posição de [Spec, IP], como parece ser a situação na configuração em (98b) do Tupinambá, mas numa posição mais acima na estrutura, possivelmente abaixo de TopP e acima do IP. Nessa linha de investigação, uma maneira é então propormos que, a sentença (99b), repetida em (102b), possui a derivação sintática indicada em (103). Nela, pressupomos que o XP circunstancial a'e rupi ocupa a posição de especificador de TopP e o DP sujeito tywyr "o irmão", a posição de especificador de FocP.

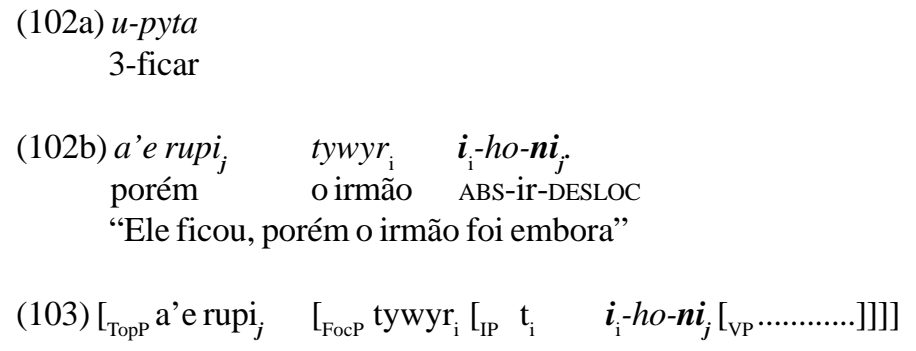

Em suma, as derivações sintáticas propostas em (97b) e (103) nos permitem afirmar que a adjacência do sujeito e do objeto em relação ao verbo, nos exemplos (87) a (96), é apenas aparente, fato que condiz com as propriedades denotacionais do prefixo $\{\mathbf{i}-\sim \mathbf{h}-\}$. Segundo essa análise, o sujeito dos verbos monoargumentais, em (87) e (88) e (90) a (94); o DP objeto awaxi "milho" do verbo transitivo subordinado, em (89b); e o objeto das nominalizações, em (95) e (96), situam todos em uma categoria funcional FP mais alta em relação àquela em que se encontra o verbo na estrutura.

\section{PROPRIEDADES MORFOSSINTÁTICAS DOS NÚCLEOS TOPํㅡ FOC ${ }^{\circ}$}

Nesta seção, exploramos a razão pela qual o verbo, embora entre na derivação com morfologia de foco nas CFOs e com o sufixo $\{-\mathbf{n}(\mathbf{i})\}$ no Indicativo II, não precisa se mover para núcleo de FocP e TopP, conforme sugerem as estruturas indicadas em (104b) e (105b) abaixo. 
$\begin{array}{clll}\text { (104a) upaw } & \text { pira } & \text { teko } & \boldsymbol{i} \text {-'u- } n \\ \text { todo } & \text { peixe } & \text { a gente } & \text { ABS-comer-DESLOC }\end{array}$

"TODO O PEIXE, a gente come"

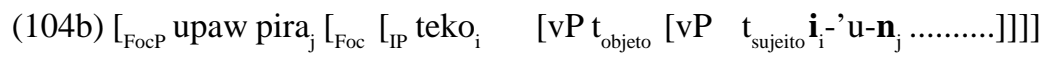

(105a) a'e pe h-eko-n

lá em ABS-estar-DESLOC

"LÁ, ele está"

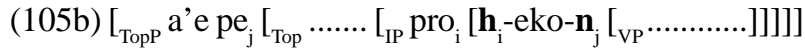

Uma possível razão pela qual o verbo se mantém em uma posição funcional mais baixa na estrutura pode ser encontrada se estipularmos que a presença apenas do DP objeto em Spec-FocP e do PP em Spec-TopP é suficiente para satisfazer ao que estipula o critério A-barra. Consoante Mioto (2001:125), esse critério prevê o seguinte:

(106) Critério A-barra

(a) Um operador $[a \mathrm{~F}]$ deve estar em configuração Spec-Núcleo com um $\mathrm{X}^{\circ}[a \mathrm{~F}]$;

(b) $\mathrm{Um} \mathrm{X}^{\circ}[a \mathrm{~F}]$ deve estar em configuração Spec-Núcleo com um operador $[a \mathrm{~F}]$.

Segundo Mioto (ibid), este "é o princípio que regula os Spec A-barra da periferia esquerda da sentença (...). O núcleo (....) determina a arquitetura do constituinte." Nessa linha de investigação, quando o núcleo $\mathrm{X}^{\circ}$ é marcado por um traço ininterpretável $[u \mathrm{~F}]$ forte, o SPEC deve estar preenchido, conforme a implicação direcional abaixo:

(107) $\mathrm{X}^{\circ}\left[\mathrm{F}_{\text {forte }}\right] \rightarrow \mathrm{OP}[\mathrm{F}]$

Todavia, quando núcleos $\mathrm{X}^{\circ}$ estão vazios, isto é indicativo de que o critério A-barra pode ser satisfeito apenas pelo preenchimento lexical do SPEC em sintaxe visível, o que atende a exigências de economia derivacional. Esta é então a situação dos núcleos $\mathrm{Foc}^{\circ} \mathrm{e}$ Top ${ }^{\circ}$ nas CFOs e no INDICATIvo II do Tenetehára e Tupinambá, visto que esses núcleos não são preenchidos pelo verbo nem por qualquer outro item gramatical. Neste aspecto, o Tenetehára e o Tupinambá diferem, por exemplo, de línguas como o Húngaro quanto à maneira de satisfazer ao critério A-barra. Puskas (1997) mostra que, nesta língua, sintagmas focalizados sempre acionam o movimento do verbo, tanto em orações principais como em orações subordinadas. Segundo a autora (ibid:152):

(108)

"The focalized constituent (...) precedes the subject both in matrix clauses and in embedded clauses and in each case the inflected verb must be right-adjacent to the focalized constituent. (...) the focalized phrase cannot be merely adjoined to a sentence with neutral order." 
Assim sendo, no Húngaro, se o verbo não estiver adjacente ao constituinte focalizado, a sentença torna-se agramatical. Para tanto, comparem-se (109a) e (109b), por um lado, e (110a) e (110b), por outro.

$\begin{array}{cllll}\text { (109a) AMARCORDOT } & \text { làtta } & \text { Jànos } & \text { tegnap } & \text { este } \\ \text { AMARCORD } & \text { saw } & \text { John } & \text { yesterday } & \text { evening }\end{array}$

"John saw AMARCORD last night"

(109b) *AmARCoRdoT Jànos làtta tegnap este

(110a)tudom hogyAMARCORDOT làtta Jànos tegnap este I-know that AMARCORD saw John yesterday evening

"I know that it was AMARCORD that John saw last night"

(110b) *tudom hogy AmARCORDOT tegnap este Jànos làtta I-know that AMARCORD yesterday evening John saw

Portanto, concluímos que, nas CFOs e no indicativo II do Tenetehára e do Tupinambá, não há exigência de que o verbo seja movido para o núcleo de FocP e TopP, enquanto, nas construções de foco do Húngaro, o verbo sempre se move para Foc ${ }^{\circ}$. Vejam que essa diferença reflete a parametrização quanto à natureza dos traços flexionais dos núcleos funcionais $\mathrm{Foc}^{\circ}$ e $\mathrm{Top}^{\circ}$ nas línguas naturais.

\section{CONSIDERAÇÕES FINAIS}

Neste texto, mostramos que o sistema nominativo-acusativo é acionado nas orações independentes sempre que o DP que ocupa a função sintática de sujeito carregar o traço-phi [+PESSOA $\left[+1_{\text {pessoa }}\right]$ e $\left.\left[+2_{\text {pessoa }}\right]\right]$ e nos casos em que o sujeito e o objeto não são pronominais. Nesses contextos, usam-se os prefixos nominativos. Já o sistema de codificação (ergativo)absolutivo é acionado nas orações temporais; nas orações independentes quando o objeto carregar o traço-phi [+PESSOA $\left[+1_{\text {pessoa }}\right]$ e $\left.\left[+2_{\text {pessoa }}\right]\right]$ e quando o sujeito for argumento de verbos monoargumentais descritivos/estativos. Nesses contextos, usa-se o prefixo absolutivo $\{\varnothing-\sim$ r-), o qual denota que o complemento está na posição de SPEC da categoria AbsP.

Por sua vez, a principal função do prefixo $\{\mathrm{i}-\sim \mathrm{h}-\}$ é marcar que o complemento não está na relação SPEC-HEAD com o verbo, em decorrência de seu deslocamento para posições A-barra, para atender a expedientes como focalização e topicalização. Quanto a esse aspecto, o Tenetehára apresenta uma possibilidade gramatical que outras línguas Tupi-Guarani não possuem, qual seja: a de acionar o prefixo $\{\mathrm{i}-\sim \mathrm{h}\}$ e do sufixo $\{-$-ni $\sim \varnothing\}$ no verbo, quando o objeto é deslocado para a posição de foco. Em outras línguas Tupi-Guarani, apenas XPs adjuntos costumam acionar essa flexão no verbo. Assim, o jogo de co-ocorrência do prefixo $\{\mathrm{i}-\sim \mathrm{h}-\}$ com o sufixo $\{-\mathrm{ni} \sim-\varnothing\}$, quer seja nas CFOs, quer seja no INDICATIVO II, aponta para elevação do objeto, do sujeito e de sintagmas XPs de natureza circunstancial para posições A-barra, fato que nos permitiu motivar as projeções funcionais TopP e FocP no domínio do CP. Portanto, a co-ocorrência do prefixo absolutivo de não-adjacência $\{\mathbf{h}-\sim \mathbf{i}-\}$ com o sufixo 
$\{-\mathbf{n}(\mathbf{i})\}$ no verbo, tanto nas CFOs como no indicativo II, demonstra que o sistema de marcação de Caso e concordância em Tenetehára é sensível a topicalizações de complementos e de adjuntos para posições A-barra, fora do domínio do IP. Esse tipo de codificação sinaliza a existência de dois padrões de concordância dos argumentos em Tenetehára, a saber: um interno à sentença, no domínio do IP, e que se dá em geral com elevação do verbo para $\mathrm{I}^{\circ}$ e do DP nominativo para Spec-IP e do DP absolutivo para Spec-AbsP; e outro externo ao IP, no qual XPs circunstanciais e focalizados se deslocam para o domínio A-barra, possivelmente para atender a expedientes de focalização e topicalização, conforme as configurações propostas abaixo.

INDICATIVO II

$$
\begin{aligned}
& \text { (111) }\left[_{\mathrm{CP}} \text { a'e } \quad \operatorname{pe}_{\mathrm{i}} \ldots \ldots \ldots . . .\left[\operatorname{pro}_{\mathbf{j}} \mathbf{i}_{\mathbf{j}} \text {-ho-ni }{ }_{\mathrm{i}}\right]\right] \\
& \text { (112) }\left[_{\mathrm{CP}} \mathrm{a}^{\prime} \mathrm{e} \quad \operatorname{pe}_{\mathrm{i}} \ldots \ldots \ldots \ldots . . .\left[\operatorname{pro}_{\mathbf{j}} \mathbf{h}_{\mathbf{j}} \text {-eko-n } \mathbf{n}_{\mathrm{i}}\right]\right]
\end{aligned}
$$

CFO

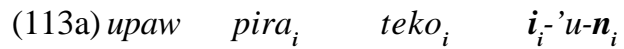
todo peixe a gente ABS-comer-DESL

"TODO O PEIXE, a gente come"

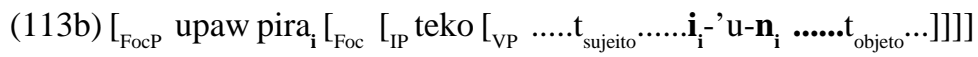

Notem que, no Indicativo II, o prefixo absolutivo $\{\mathbf{i}-\sim \mathbf{h}-\}$ aponta para o sujeito nulo pro, que está em [SPEC-IP], ao passo que, nas CFOs, este mesmo prefixo assinala a elevação do DP objeto upaw pira para fora do predicado, mais especificamente para a posição de [SPEC-FocP].

Por fim, propusemos que o critério A-barra em Tenetehára e em Tupinambá é satisfeito sem que o núcleo de FocP e TopP seja lexicalmente preenchido, o que explica, portanto, a razão pela qual o verbo figura numa posição estrutural mais baixa em relação à posição que o seu argumento (interno ou externo) ocupa, no domínio CP.

\section{REFERÊNCIASBIBLIOGRÁFICAS}

BENDOR-SAMUEL, D. (1972). Hierarchical structures in Guajajara. Norman: Summer Institute of Linguistics, University of Oklahoma.

BOUDIN, M.H. (1966). Dicionário de Tupi moderno. São Paulo, Faculdade de Filosofia, Ciências e Letras de Presidente Prudente.

.(1978). Dicionário de Tupi moderno. São Paulo, Conselho Estadual de Artes e Ciências Humanas, 2 v.

CABRAL, A.S.A. da C. (2000). Flexão relacional na família Tupi-Guaraní. Belém: UFPA. Ms.

CHOMSKY, N. (1995). The minimalist program. Cambridge, Mass.: MIT Press.

COELHO, E.M.B. (1987). Levantamento da situação das áreas indígenas no Maranhão: relatório de pesquisa. São Luís: Editora da Universidade Federal do Maranhão. 
DINIZ, E.S. (1994). Os Tenetehára-Guajajara e a sociedade nacional: flexibilidade cultural e persistência étnica. Belém: Editora Universitária, Universidade Federal do Pará/CNPq.

DIXON, R.M.W. (1979). Ergativity. Language, 55: pp.59-138.

DUARTE, F.B. (1997). Análise gramatical das orações da língua Tembé. Dissertação de Mestrado. Brasília: Instituto de Letras/LIV, UnB. (1998). Ordem dos Constituintes na Língua Tembé. Revista da Universidade Católica de Brasília 6(1): pp. 71-80.

(2002a). Construções de gerúndio na língua Tembé. Revista LIAMES 1: pp.77-90. Campinas:UNICAMP.

.(2002b). Negação e movimento do verbo na língua Tembé. Atas do I Encontro Internacional do Grupo de Trabalho sobre Línguas Indígenas da ANPOLL, t. 1: pp.374-384. Belém: UFPA.

.(2003). Ordem de constituintes e movimento em Tembé: minimalismo e anti-simetria. Tese de Doutorado em Lingüística. Belo Horizonte: UFMG.

.(2004a). Propriedades denotacionais dos prefixos $\{\mathrm{i}-\}$ e $\{\mathrm{h}-\}$ em Tenetehára. Campinas: UNICAMP. Comunicação apresentada no $52^{\circ}$ Seminário do GEL. Ms.

.(2004b). Verbos auxiliares, extraposição de projeções máximas e scrambling na ordem básica dos constituintes na Língua Tembé. Juiz de Fora:UFJF. Ms.

.(2004c). On the scope of verb movement in the Tenetehara Language. Comunicação proferida durante o I EVELIN, Campinas: UNICAMP, janeiro 2004. Ms.

.(2004d). Expressão da quantificação em Tenetehara. Brasília: UnB. Comunicação apresentada durante o I Encontro de Línguas e Culturas Tupi. Ms.

(2005a). Control constructions in Tenetehara. Campinas: UNICAMP, Comunicação apresentada durante o II EVELIN, janeiro 2005. Ms.

.(2005b) Propriedades denotacionais dos prefixos $\{\mathrm{i}-\sim$ h- $\}$ em Tenetehára. Revista de Estudos Lingüísticos/GEL XXXIV: pp. 1194-1199.Campinas: Unicamp.[http://www.gel.org.br/ 4publica-estudos-2005].

GALÚCIO, A.V. (2002). O prefixo i- em Tupi: morfema antipassivo vs marcador pronominal incorporado. Atas do I Encontro Internacional do Grupo de Trabalho sobre Línguas Indígenas da ANPOLL t. I: pp. 274-287. Belém: UFPA.

GRANNIER, Daniele Marcelle. (2005). A natureza dos prefixos relacionais em Guarani Antigo. In Aryon Rodrigues \& Ana Suelly Cabral (Orgs.). Novos Estudos sobre Línguas Indígenas, pp. 129-140. Brasília: Editora UnB.

HARRISON, C. (1986). Verb prominence, verb initialness, ergativity and typological disharmony in Guajajara. In D. C. Derbyshire \& G. K Pullum (Eds.). Handbook of Amazonian Languages, v. 1: 407-439. Berlin: Mouton de Gruyter.

JENSEN, C. (1990). Cross-referencing changes in some Tupi-Guarani languages. In Doris L. Payne (Ed.) Amazonian Linguistics: Studies in Lowland South American Languages, pp. 117-158. Austin: University of Texas Press.

KAYNE, R.S. (1994). The antisymmetry of syntax. Cambridge, Mass.: MIT Press.

LEVIN, B. \& HOVAV, M. Rappaport. (1995). Unaccusativity: At the Syntax-Lexical Semantics Interface. Cambridge, Mass.: MIT Press.

MIOTO, C. (2001). Sobre o sistema CP no português brasileiro. Revista Letras 56: pp.97-140. Curitiba: UFPR.

PUSKAS, G. (1997). Focus and the CP domain. In L. Haegeman (Ed.). The New Comparative Syntax, pp.145-164. London: Longman. 
RAPOSO, E.P. (1999). O Programa minimalista - Noam Chomsky. Portugal, Lisboa: Editorial Caminho.

RICARDO, C.A. (1985). Povos indígenas no Brasil. São Paulo: CEDI (Centro Ecumênico de Documentação e Informação)

RICE, F.J.D. (1934). O idioma Tembé (Tupi-Guarany). Journal de la Société des Américanistes 26: 109-180. Paris.

RIZZI, L. (1990). Relativized minimality. Cambridge. Mass.: MIT Press. .(1997). The Fine Structure of the Left Periphery. In L. Haegeman (Ed.). Elements of Grammar:Handbook of Generative Syntax, pp. 281-337. Kluwer: Dordrecht.

RODRIGUES, A.D. (1953). Morfologia do Verbo Tupi. Letras 1: pp.121-152. Curitiba. .(1986). Línguas brasileiras: para o conhecimento das línguas indígenas. Rio de Janeiro: Loyola. .(2000). Sobre a natureza do caso argumentativo. In F. Queixalós (Ed.). Des noms et des verbs em Tupi-Guarani, état de la question, pp. 63-74. Caiena: IRD e CNRS.

(2001). Alguns problemas em torno da categoria lexical verbo em Línguas Tupi-Guarani. In Ana S. Cabral \& Aryon Rodrigues (Orgs.). Estudos sobre Línguas Indígenas 1: pp.87-100. Belém: UFPA/GTLI.

SEKI, L. (1990). Kamaiurá (Tupí-Guaraní) as an Active-Stative Language. In Doris Payne (Ed.) Amazonian Linguistics: Studies in Lowland South American Languages, pp. 367-390. Austin: University of Texas Press.

.(2000). Gramática do Kamaiurá: língua Tupi-Guarani do Alto Xingu. Campinas: Editora da UNICAMP e Imprensa Oficial de São Paulo.

SHOPEN, T. (1986). Language Typology and Syntatic Description. Cambridge: Cambridge University Press, 3 v.

WAGLEY, C. E GALVÃO, E. (1955). Os Índios Tenetehára: uma cultura em transição. Rio de Janeiro: Ministério da Educação e Cultura.

\section{APÊNDICE}

\section{ABREVIATURAS}

AbsP: categoria funcional atribuidora de Caso absolutivo; AP: marca discursiva cuja ocorrência depende do sexo dos interlocutores; ARG: DP na função de argumento do verbo; AUX: verbo Auxiliar; $\mathrm{C}^{0}$ : núcleo de CP; CAUs: prefixo causativo; Col: sufixo que indica coletivo/plural do nome; comp: complementizador; COR: prefixo de correferencialidade (w- o- u- \}; DAT: dativo; DISC: marcador discursivo; DESLOC/DESL: sufixo que sinaliza movimento de constituintes XPs argumentais ou adjuntos para o domínio CP; DPASS: passado distante; DPASTU: passado distante não atestado; FOC: foco; FUT: sufixo indicativo do futuro; INTS: Intensificador IPASS: passado imediato; NEG: negação; NOM: caso nominativo; NOML: nominalizador; NP: sintagma nominal; PP: sintagma posposicional; oвJ: prefixo verbal que indica o Caso absolutivo ao DP na função sintática de objeto; OBLQ: caso oblíquo; oBs: prefixo verbal que indica o Caso absolutivo; PL: marcador do plural; Q: quantificador; тop: Tópico.

\section{ORTOGRAFIA USADA}

Considerando o padrão fonêmico dos sons da língua Tenetehára, adoto a seguinte ortografia cujo objetivo principal é facilitar a leitura dos dados usados em nossa análise. Os grafemas são:

(i) consoantes $\mathrm{p}, \mathrm{t}, \mathrm{k}$, , $, \mathrm{m}, \mathrm{n}, \mathrm{g}, \mathrm{gw}, \mathrm{k}, \mathrm{kw}, \mathrm{z}, \mathrm{x}, \mathrm{h}, \mathrm{r}, \mathrm{w}$

(ii) vogais: a, e, i, o, u, y, à 
Os grafemas $\boldsymbol{g}$ e $\boldsymbol{g} \boldsymbol{w}$ correspondem respectivamente ao fonema velar $/ \mathrm{y} /$ e ao labiovelar $/ \mathrm{y} w / ;$ o grafema $\mathbf{z}$, ao som alveolar oclusivo /d/ e todos os seus variantes; o grafema $\mathbf{x}$, ao som alveolar fricativo $/ s /$ e seu variante $/ \mathrm{t} \mathrm{J} /$; e o diacrítico ' ao fonema glotal $/ 2 /$. Finalmente, os grafemas y e à equivalem, respectivamente, à vogal central alta /ì e à vogal central média /\% / lll

\section{MARCADORES DE CASO}

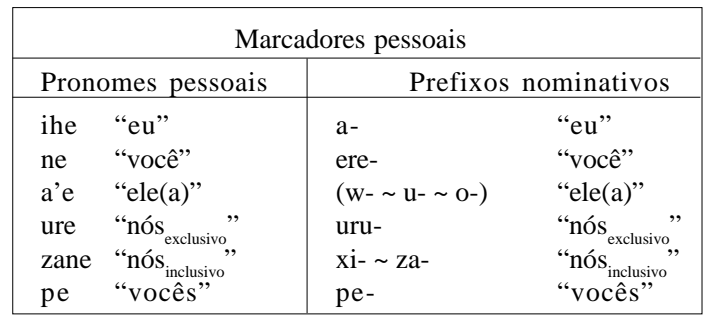

\begin{tabular}{|l|c|c|}
\hline \multicolumn{2}{|c|}{ Prefixos absolutivos } \\
\hline & $\begin{array}{l}\text { tema em } \\
\text { consoante }\end{array}$ & tema em vogal \\
\hline $\begin{array}{l}\text { adjacência do } \\
\text { complemento } \\
\text { não adjacência } \\
\text { do complemento }\end{array}$ & i- & r- \\
\hline
\end{tabular}

\section{PARADIGMAS DE CONJUGAÇÕES VERBAIS}

\subsection{Sistema de codificação nominativa}

\begin{tabular}{|c|c|c|}
\hline & Verbo "matar" & -zuka \\
\hline ihe & a-zuka & "eu matei (algo)" \\
\hline ne & re-zuka & "tu mataste (algo)" \\
\hline a'e & u-zuka & "ele matou (algo)" \\
\hline ure & uru-zuka & "nós exclusivo matamos (algo)" \\
\hline zane & xi-zuka & 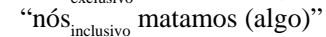 \\
\hline pe & pe-zuka & "vós matastes (algo)" \\
\hline a'e & u-zuka wà & "eles mataram (algo)" \\
\hline \multicolumn{3}{|c|}{ Verbo "ver" -exak } \\
\hline ihe & a-exak & “eu vi (algo)” \\
\hline ne & re-xak & "tu viste (algo)" \\
\hline a'e & w-exak & "ele viu (algo)" \\
\hline ure & uru-exak & "nós exclusivo vimos (algo)" \\
\hline zane & xi-exak & "nós ${ }_{\text {inclusivo }}$ vimos (algo)" \\
\hline pe & pe-xak & "vós vistes (algo)" \\
\hline a'e & w-exak wà & "eles viram (algo)" \\
\hline
\end{tabular}


Verbo "caminhar" -wata

$\begin{array}{lll}\text { ihe } & \text { a-wata } & \text { "eu caminhei" } \\ \text { ne } & \text { re-wata } & \text { "tu caminhaste" } \\ \text { a'e } & \text { u-wata } & \text { "ele caminhou" } \\ \text { ure } & \text { uru-wata } & \text { "nós exclusivo caminhamos" } \\ \text { zane za-wata } & \text { "nós } \\ \text { pe } & \text { pe-watlusivo caminhamos" } \\ \text { a'e u-wata wà } & \text { "vós caminhastes" } \\ \end{array}$

4.2. Sistema de codificação (ergativo)-absolutiva

Verbo “matar" -zuka

$\begin{array}{lll}\text { ihe } & \varnothing \text {-zuka } & \text { "(algo) me matou" } \\ \text { ne } & \varnothing \text {-zuka } & \text { "(algo) te matou" } \\ \text { ure } & \varnothing \text {-zuka } & \text { "(algo) nos } \text { exclusivo }_{\text {-zatou" }} \text { matou" } \\ \text { zane } & \varnothing \text {-zuka } & \text { "(algo) nos } \\ \text { pe } & \varnothing \text {-zuka } & \text { "(algo) vos matou" }\end{array}$

Verbo "ver" -exak

ihe r-exak "(algo) me viu"

ne r-exak "(algo) te viu"

ure r-exak "(algo) nos exclusivo $_{\text {viu" }}$

zane r-exak "(algo) nos inclusivo viu"

pe r-exak "(algo) vos viu"

Verbo "estar alegre" -urywete

ihe r-urywete "eu estou alegre"

ne r-urywete "tu estás alegre"

a'e h-urywete "ele está alegre"

ure "r-urywete "nós exclusivo $_{\text {estamos alegres" }}$

zane r-urywete "nós $s_{\text {inclusivo }}$ estamos alegres"

pe r-urywete "vós estais alegres"

a'e h- urywete wà "eles estão alegres"

Verbo "estar bem" -katu

ihe $\emptyset$-katu "eu estou bem"

ne Ø-katu "tu estás bem"

a'e i- katu "ele está bem"

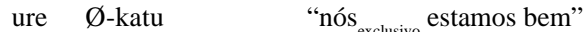

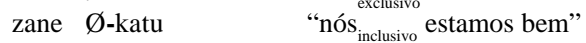

pe Ø-katu "vós estais bem"

a'e i- katu wà "eles estão bem"

Recebido: 15/04/2005

Versão Corrigida: 14/09/2005

Aprovado: 30/10/2005 